\title{
Research@ZaB: Study of FDS Capabilities to Assess the High-Speed Train Impact on Pressure Pattern Within a Railway Tunnel
}

\author{
Aliaksei Patsekha and Robert Galler \\ Chair of Subsurface Engineering, Montanuniversität Leoben, Leoben, Austria
}

Received October 11, 2021; accepted October 25, 2021; published online November 25, 2021

\begin{abstract}
The "wind tunnel" approach is applied to study high-speed train aerodynamics in a railway tunnel using FDS software. The main focus of the research is on the pressure distribution along the tunnel. Proven analytical dependencies based on the experimental observations for air jet centerline velocity and flow entrainment are used to evaluate the model setup. A model verification is carried out based on the pressure drop calculations due to viscous effects where the impact of the surface roughness and the tunnel length are also considered. A sensitivity analysis is performed to evaluate changes in input FDS parameters and to explore interactions between them. It is proposed to use the standard deviation, obtained from the calculated time-averaged pressure values, to specify the appropriate numeric parameter combinations, e.g. DT and PRESSURE_TOLERANCE, considering the desired results consistency and the computational time consumed. The simulated cases with and without a train inside a tunnel provide data on the aerodynamic characteristics of the models. The obtained volumetric and cross-sectional profiles for pressure and airflow velocity distribution form the basis for an informed decision regarding the tunnel design or safety solutions, for example, defining areas under maximal and minimal pressure loads. The analysis displays the necessity to carefully manage each investigated case considering the FDS features and limitations that largely affect a model setup and calculations.
\end{abstract}

Keywords: Pressure distribution, Simulation, Tunnel, High-speed train, Fire Dynamics Simulator

\footnotetext{
A. Patsekha $(\bowtie)$

Chair of Subsurface Engineering,

Montanuniversität Leoben,

Erzherzog Johann Straße 3,

8700 Leoben, Austria

aliaksei.patsekha@unileoben.ac.at
}

Research@ZaB: Untersuchung der FDS-Fähigkeiten zur Beurteilung der Auswirkungen von Hochgeschwindigkeitszügen auf den Druckverhalten in einem Eisenbahntunnel

Zusammenfassung: Die Aerodynamik von Hochgeschwindigkeitszügen in einem Eisenbahntunnel wird mittels „Windkanal“-Ansatz der FDS-Software untersucht. Der Schwerpunkt der Forschung liegt auf der Druckverteilung entlang des Tunnels. Bewährte analytische Abhängigkeiten basierend auf experimentellen Beobachtungen für die Geschwindigkeit der Luftstrahlmittellinie und die Strömungsmitnahme werden verwendet, um den Modellaufbau zu bewerten. Die Modellüberprüfung erfolgt auf Basis der Druckverlustberechnungen aufgrund viskoser Effekte, wobei auch der Einfluss der Oberflächenrauheit und der Tunnellänge berücksichtigt wird. Die Durchführung einer Sensitivitätsanalyse erlaubt Änderungen der eingegebenen FDS-Parameter zu bewerten und ihre Wechselwirkungen untereinander zu untersuchen. Es wird vorgeschlagen, die Standardabweichung der berechneten zeitgemittelten Druckwerten zu verwenden, um die entsprechenden numerischen Parameterkombinationen anzugeben, z. B. DT und PRESSURE_TOLERANCE, unter Berücksichtigung der gewünschten Ergebniskonsistenz und der benötigten Rechenzeit. Die simulierten Fälle mit und ohne Zug in einem Tunnel liefern Daten über die aerodynamischen Eigenschaften der Modelle. Die erhaltenen Volumen- und Querschnittsprofile für die Druck- und Strömungsgeschwindigkeitsverteilung bilden die Grundlage für eine fundierte Entscheidung hinsichtlich der Tunnelkonstruktion oder Sicherheitslösungen, beispielsweise zur Definition von Bereichen unter maximaler und minimaler Druckbelastung. Die Analyse zeigt die Notwendigkeit, jeden untersuchten Fall unter Berücksichtigung der FDS-Funktionen und -Einschränkungen, die den Modellaufbau und die Berechnungen stark beeinflussen, sorgfältig zu verwalten. 
Schlüsselwörter: Druckverteilung, Simulation, Tunnel, Hochgeschwindigkeitszug, Fire Dynamics Simulator

\section{Introduction}

The network of high-speed trains has recently been rapidly developed due to a number of economic and social benefits (high travel speed and time savings, large transportation capacity and traffic flow increase, reliability and safety performance, etc.). In 2020, the length of the operational high-speed railway reached $52,418 \mathrm{~km}$ around the world, while additionally $11,693 \mathrm{~km}$ of high-speed lines are under construction [1]. Furthermore, some countries consider the high-speed rail network extension as a key component in their overall economic development policy and expect certain positive impacts on regional, urban, and station area levels $[2,3]$.

However, along with the obvious benefits, an increase in train speed causes various engineering issues related to aerodynamic performance and operational safety. The situation even worsens when a railway train passing at a high speed through a tunnel is considered. This train-tunnel interaction induces the following aerodynamics problems: aerodynamic drag, piston effect, slipstream, pressure (inside tunnels and trains) and micro-pressure (at exits of tunnels) waves, noise and vibration, and more $[4,5]$.

Studies of aerodynamic effects occurring while trains are passing through tunnels are widely covered in recent publications. Scientists investigate the aerodynamic performance of a high-speed train in a tunnel involving fullscale experiments, scale modelling tests, and numerical simulations [6-8]. Herein, particular attention is given to aerodynamic pressure effects resulting from the increasing speed of high-speed trains as the generated pressure fluctuations affect heavily the safety of a train body and tunnel facilities and cause damages $[9,10]$. Furthermore, pressure gradients cause train passengers discomfort and occasionally medical problems and can be rather dangerous for tunnel workers and people at a trackside or on a platform. To address this issue, a certain number of studies were conducted to investigate this aerodynamic phenomenon [11-13]. The results of this research field became the foundation for standard procedures and the development of the aerodynamic loading limits that were reflected in the Technical Specification for Interoperability and European standard EN $14067[14,15]$.

Recent publications show a great value of computational fluid dynamics (CFD) in assessing the aerodynamic performance of a high-speed train passing through a tunnel and resolving physical tasks involving flow field characteristics in the process [16-18].

The research motivation of this study is to explore the capabilities of the Fire Dynamics Simulator (FDS) to investigate the aerodynamics of the airflow generated by a high-speed train passing through a tunnel. FDS is a largeeddy simulation code developed by the National Institute of Standards and Technology (NIST) of the United States Department of Commerce. This open-source software is designed to solve the spatially filtered form of the Navier-
Stokes equations appropriate for incompressible flow in wind engineering applications [19]. Pressure values are commonly used for numerical assessment of operational safety and tunnel structural strength. For this reason, the main focus of the study is pressure loading on a train body and inner tunnel surfaces.

\section{Research Approach and Methodology}

Usually, the field of train aerodynamics is investigated using static and moving experimental layouts. FDS assumes a permanent positioning of solid models providing conditions only for simulation of a static experiment: a fixed model and an incoming wind speed. This approach is generally applied for carrying out tests in wind tunnels where the air moves around a stationary object thereby producing the same effect as if this object was moving through the air.

The main challenge of the study is adjusting the FDS (version 6.7.5) model to the tasks to be solved because typically a moving model needs to be considered to predict the flow structure around a train passing through a tunnel [20]. A suggestion is made to observe an actual non-stationary phenomenon of a moving train as a sequence of stationary cases within the assigned time intervals.

\subsection{Air Jet Applicability and Convergence Study}

The centerline velocity represents one of the main flow characteristics that provides an opportunity to compare the model setup and its adequacy to experimental data. Baturin provided the following equation [21]:

$$
u_{m}(x)=\frac{0.48 u_{0}}{\left(a x / d_{0}+0.145\right)}
$$

Where $u_{m}$ is the centerline velocity $(\mathrm{m} / \mathrm{s}), u_{0}$ is the supply velocity $(\mathrm{m} / \mathrm{s}), a$ is a constant that varies between 0.076 and $0.080, x$ is distance from the supply $(\mathrm{m})$ and $d_{0}$ is the supply diameter $(\mathrm{m})$.

Kümmel presented another formula based on his experimental observations [22]:

$$
u_{m}(x)=\frac{u_{0}}{m x} \sqrt{b h}
$$

Where $b$ is the width of a rectangular nozzle orifice $(\mathrm{m})$, $h$ is the height of a rectangular nozzle orifice $(m), m$ is a constant that varies between 0.12 and 0.20 .

The railway tunnel at the "Zentrum am Berg" facility is viewed as a prototype for modelling. The size of a supply orifice $(b=8 \mathrm{~m}, h=7 \mathrm{~m})$ is chosen considering the tunnel entrance dimensions. An arc tunnel cross-section area is represented using a stair-stepped shape to satisfy the FDS domain boundary conditions. Thus, the Baturin (1) and Kümmel (2) bounds are calculated for a rectangular outlet $(7.0 \times 8.0 \mathrm{~m})$ with an equivalent diameter of $8.44 \mathrm{~m}$ (according to AMCA Standard 201) and an initial air velocity of $69.44 \mathrm{~m} / \mathrm{s}$ (it is assumed that the train speed is $250 \mathrm{~km} / \mathrm{h}$ ).

Flow entrainment is also used to compare simulation results with the empirical data. Ricou and Spalding sug- 


\begin{tabular}{|llll|}
\hline $\begin{array}{l}\text { TABLE 1 } \\
\text { Information on simulation parameters }\end{array}$ \\
\hline $\begin{array}{l}\text { Simulation } \\
\text { Set }\end{array}$ & Cell size, $\mathrm{m}$ & $\begin{array}{l}\text { Number of } \\
\text { meshes }\end{array}$ & $\begin{array}{l}\text { Number of } \\
\text { cells }\end{array}$ \\
\hline 1 & $1.0 \times 0.5 \times 0.5$ & 8 & 912,000 \\
\hline 2 & $0.5 \times 0.25 \times 0.25$ & 8 & $7,296,000$ \\
\hline 3 & $0.4 \times 0.2 \times 0.2$ & 8 & $14,250,000$ \\
\hline
\end{tabular}

gested the following equation based on their experimental measurements [23]:

$$
Q(x)=0.32\left(\frac{x}{d_{0}}\right) \times Q_{0}
$$

Where $Q$ is the volume flow rate at distance $x\left(\mathrm{~m}^{3} / \mathrm{s}\right)$ and $Q_{0}$ is the supply flow rate $\left(\mathrm{m}^{3} / \mathrm{s}\right)$.

Four turbulence models from FDS are evaluated to find the best agreement of an analytical approach with simulation results [24, 25]: Deardorff (default by FDS), Constant Smagorinsky, Dynamic Smagorinsky and Vreman.

Previous calculations showed the high dependency of FDS results on the used grid resolution [26]. Reducing the grid cell size does not necessarily mean a significant increase in precision. However, it does considerably extend the simulation runtime [27]. So, a balance between the desired precision and the program execution time is preferable.

For each turbulence model, three grid resolutions are considered for the computational domain (Table 1).

The simulation results are analysed in the form of averaged values (for centerline velocity and flow entrainment) as the used simulation mode VLES (Very Large Eddy Simulation) defines the turbulence model equations where instantaneous numbers can be misleading. Thus, the period from 10 to $15 \mathrm{~s}$ is captured for evaluation to represent steady-state measurements.

A better fit mesh cell resolution is decided by comparing the predicted centerline velocity and flow entrainment with those from Eq. 1-3. An example of the resulting curves for the Constant Smagorinsky turbulence model is given in Fig. 1.

As a result, the third grid resolution of $0.4 \times 0.2 \times 0.2 \mathrm{~m}$ (Set 3) used in combination with the Constant Smagorinsky turbulence model is chosen for the subsequent calculations.

\subsection{Simulation Setup and Modelling}

A single mesh computational domain is considered for the simulation. It is preferred for domains with multiple meshes due to the occurrence of a numerical instability in the form of pressure fluctuations. The domain has an $8.0 \times 7.2 \mathrm{~m}$ (width $\times$ height) cross-section and a length of $300 \mathrm{~m}$. Domain boundaries by coordinates are: $0.0 \ldots 300.0 \mathrm{~m}$ ( $\mathrm{X}$ coordinate), $-4.0 \ldots+4.0 \mathrm{~m}(\mathrm{Y})$, $-0.2 \ldots+7.0 \mathrm{~m}(\mathrm{Z})$.

The simulated tunnel represents a straight $300 \mathrm{~m}$ long construction at one end of which (the exterior boundary of the computational domain) there is an "open" surface that performs as a passive opening to the outside ("Open" boundary condition); at the other end a "Supply vent" to provide necessary airflow is situated. The cross-sectional area of the tunnel adapted to the domain grid resolution is $41.76 \mathrm{~m}^{2}$.

A train model for the simulation consists of three carriages: front car (length $27.4 \mathrm{~m})$, middle car $(25.0 \mathrm{~m})$, back car $(27.4 \mathrm{~m})$. The Shinkansen 700 Series train is considered as a basis. Therefore, the carriage models are built on the data from [28]. The whole train length is $80.6 \mathrm{~m}$.

A flat ground is assumed as the ground configuration similarly to a train test in a wind tunnel.

The simulation model of the train placed in the tunnel is presented in Fig. 2.

Several sets of FDS devices to record aerodynamic parameters (e.g., pressure, velocity, volume flow) are included in the model. In the description of the simulation results, the term "centerline" would characterize the mea-
Fig. 1: Comparison of the simulation results for the Constant Smagorinsky turbulence model with corresponding analytical values: a free air jet centerline velocities; b flow entrainment

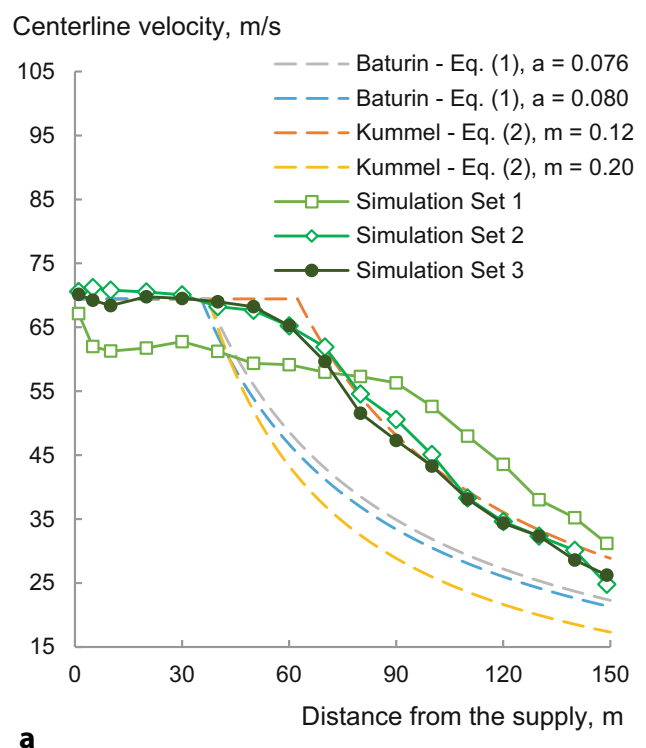

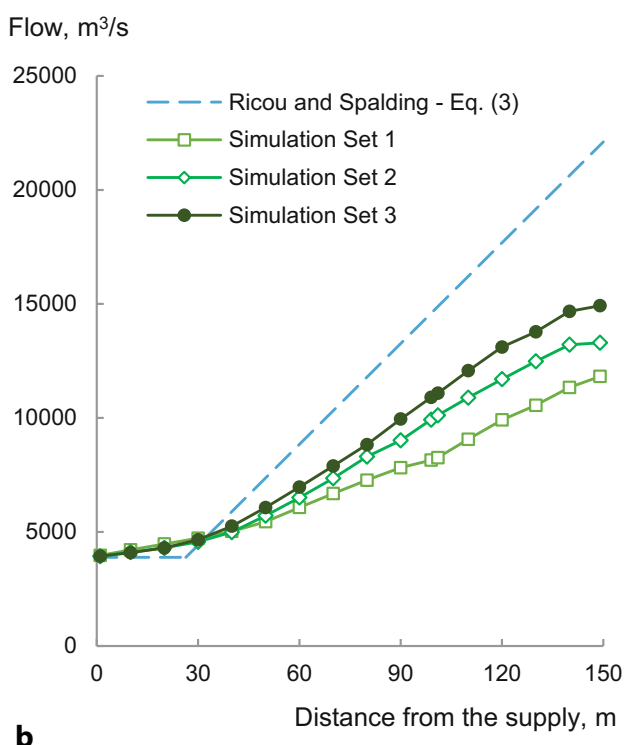


Fig. 2: Model view of the train in the tunnel

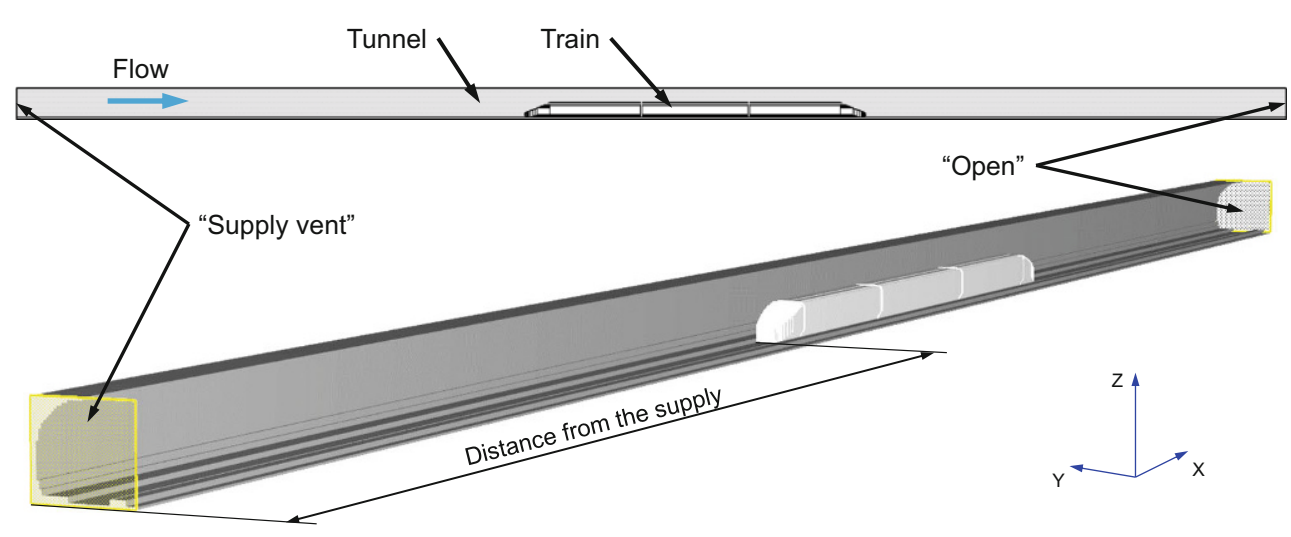

Fig. 3: Comparison of the predicted and theoretical pressure values along the tunnel (error bars show the $95 \%$ confidence interval)

Mean pressure, $\mathrm{Pa}$

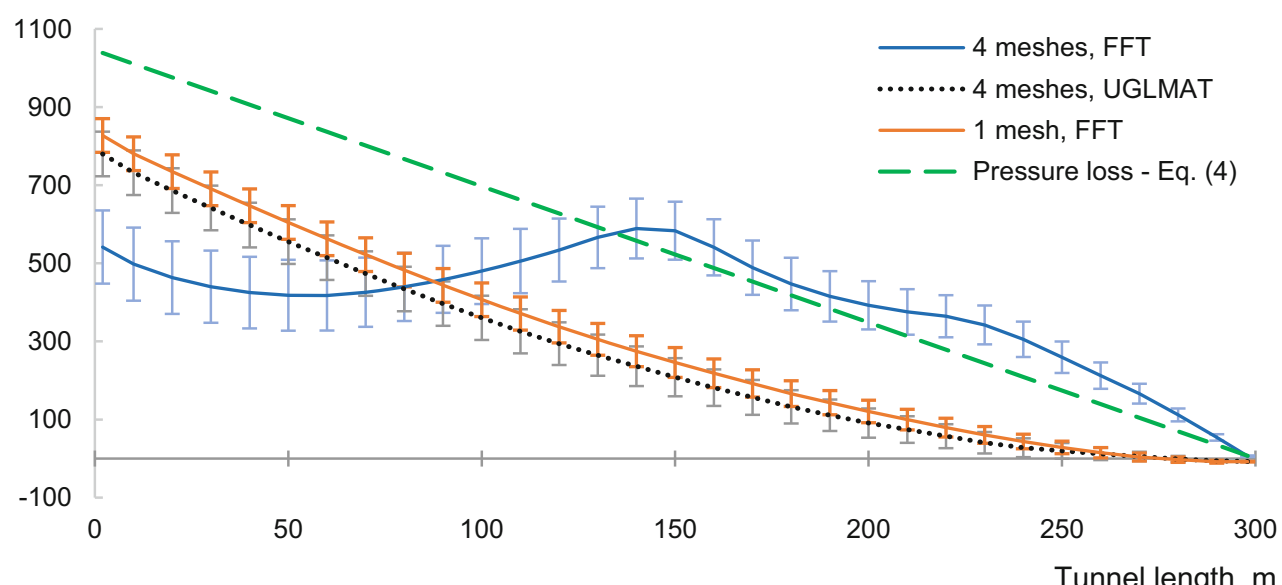

suring devices located at the central axis of the tunnel (coordinate $Y=0$ ) at $3.4 \mathrm{~m}$ height from the train track. The term "side" would mean that devices are placed at the left tunnel side at $1.2 \mathrm{~m}$ above the platform $(Z=1.6 \mathrm{~m})$ and $3.0 \mathrm{~m}$ from the track centre $(Y=2.6 \mathrm{~m})$.

The simulation duration time is chosen as 30 s to obtain steady-state conditions throughout the tunnel.

Preliminary tests allowed comparing the default FFT (Fast Fourier Transforms) pressure FDS solver with an alternative UGLMAT solver coupled with a 4-mesh domain (Fig. 3). During the analysis, the predicted data stability, including the standard deviation values, maximum velocity and pressure errors and simulation runtime (the UGLMAT solver is more than double the runtime of the FFT solver) were considered. A single mesh computational domain and the FFT-based pressure solver proved to be the most suitable option for the current setup.

\subsection{Model Verification}

The tunnel model without a train inside is reviewed for verification purposes.

According to the study goals, the pressure value in the tunnel is viewed as the main quantitative characteristic. It is proposed to use the analytically obtained pressure dis- tribution inside the tunnel as a revision tool in the analysis of the predicted values.

The pressure drop due to viscous effects represents an irreversible pressure loss [29]:

$$
\Delta P=f \frac{L}{D} \frac{\rho V^{2}}{2}
$$

Where $\Delta P$ is the pressure drop (Pa), $f$ is the Darcy friction factor (the Swamee-Jain equation is used to determine $f[30]), L$ is the tunnel length $(\mathrm{m}), \rho$ is the density of the fluid $\left(\mathrm{kg} / \mathrm{m}^{3}\right), V$ is the average velocity of the fluid in the tunnel $(\mathrm{m} / \mathrm{s}), D$ is the tunnel hydraulic diameter $(\mathrm{m})$.

Calculations show a clear difference between the curves "1 mesh, FFT" (the applied setup) and "Pressure loss-Eq. 4" in Fig. 3. To improve the agreement of the results, other turbulence models (Deardorff, Dynamic Smagorinsky, and Vreman) are additionally explored.

The reasonability to implement the 'DYNAMIC SMAGORINSKY' turbulence model in the current case is evident from Fig. 4. It provides a very good convergence with the theoretically obtained pressure values, considering the outlined confidence interval with the significance level of 0.05 , as the biggest difference in pressure is $68.8 \mathrm{~Pa}$ or $6.7 \%$.

Moreover, a pressure drop with an increasing magnitude of the pressure gradient is observed at the entrance (near the vent supply) section of the 'DYNAMIC SMAGORINSKY' 
Fig. 4: Theoretical pressure loss and mean pressure values for four turbulence models
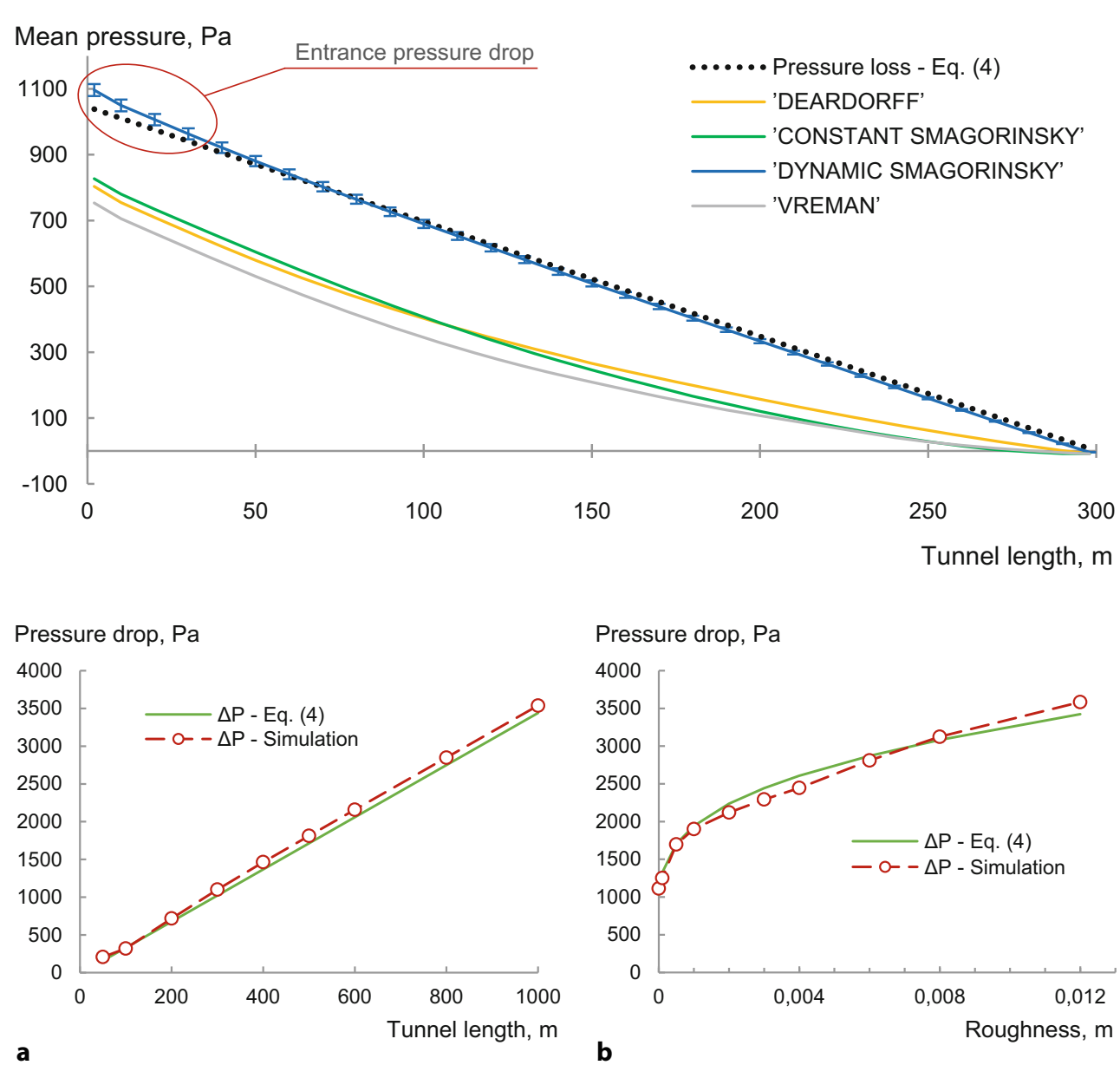

a
Fig. 5: Comparison of analytical and predicted pressure losses depending on: a tunnel length; b tunnel surface roughness
Where $\varepsilon$ is the roughness $(\mathrm{m})$ and $R e$ is the Reynolds number, $R e=V D / v$ (here $v$ is the kinematic viscosity).

A good congruence between the predicted and theoretical pressure losses is observed (Fig. 5b) as the biggest difference between the corresponding values does not exceed $6.7 \%$.

Thus, it can be concluded that the chosen model setup provides an acceptable level of credibility of the analysed criteria and can be used further in the subsequent study.

\subsection{Sensitivity Analysis}

The sensitivity analysis is performed to improve the predictions of the model and their accuracy by studying the model response to changes in input parameters.

The following FDS parameters were considered:

- the initial time step size DT in s (defines a step in the time duration of the simulation whilst the average values of quantitative parameters are calculated over the resulted time interval);

- the PRESSURE_TOLERANCE in s ${ }^{-2}$ (can alleviate the mismatch between existing and generated pressure fields);

- the VELOCITY_TOLERANCE in $\mathrm{m} / \mathrm{s}$ (enables a tighter match of velocities at the mesh boundaries);

$$
f=\frac{0.25}{\left[\log _{10}\left(\frac{\epsilon / D}{3.7}+\frac{5.74}{R e^{0.9}}\right)\right]^{2}}
$$


Fig. 6: Dependency between the DT and

PRESSURE_TOLERANCE

combination and the standard deviation for the pressure losses, calculated within the tunnel length
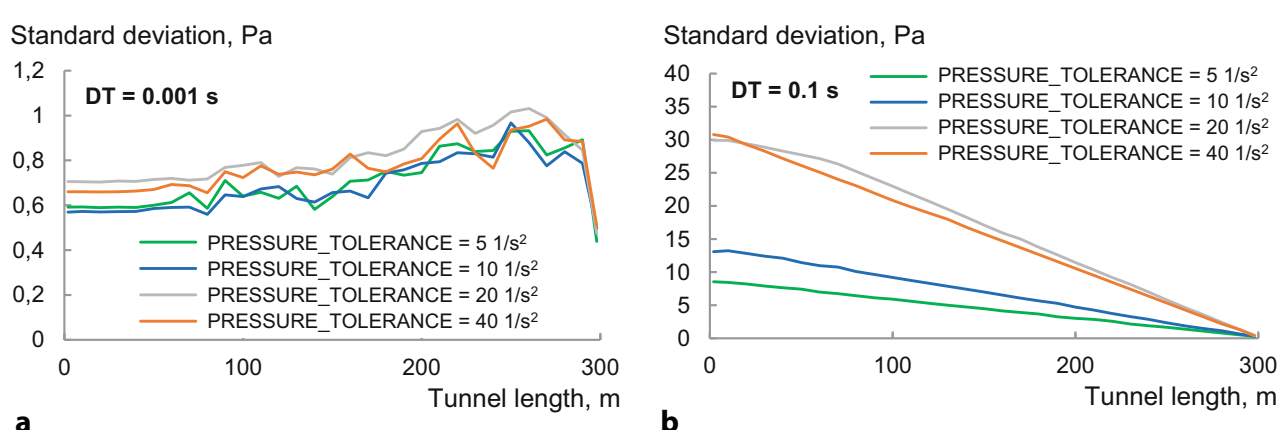

- the maximum number of pressure iterations MAX_PRESSURE_ITERATIONS (allows to control the calculational error in pressure values).

The set of the initial time steps DT $(0.001,0.002,0.005,0.01$, $0.05,0.1 \mathrm{~s}$, and the default value of $0.148 \mathrm{~s})$ is examined in the process. The selected velocity $(0.01,0.05,0.1$, and $0.2 \mathrm{~m} / \mathrm{s})$ and pressure $\left(5,10,20,40\right.$, and $\left.125 \mathrm{~s}^{-2}\right)$ tolerances, based on the expected factor ranges and corresponding relative errors, are analysed in view of their impact on pressure and other aerodynamic parameters. In the study, the required error tolerance for pressure is usually achieved through the pre-defined amount of iterations (10 by default). Thus, the value of MAX_PRESSURE_ITERATIONS is set as 50 to ensure the simulation is not suspended because of a large error in the calculations.

A planning matrix used for modelling during the sensitivity analysis includes 74 parameter sets. It is defined that the influence of the separate factors and their combinations on the calculations is very limited within the given setup and does not drastically affect the calculated quantities. The following notable results are worth mentioning here.

Lesser DT values (0.001 and $0.002 \mathrm{~s})$ lead to a pressure decrease up to $7.3 \%$ (comparing to the default DT value) almost through the whole tunnel length.

The numerical values of pressure and velocity tolerances do not drastically affect the calculated pressure loss in the tunnel. Partly it can be explained by reaching levels for maximum pressure and velocity errors similar to the simulation within the default parameter settings.

Overall, it can be noted that the initial time step fulfils the role of the dominant factor in pressure calculations and the impact of other parameters or their combinations is sufficiently small.

Fig. 7: Cross-sectional velocity changes by the tunnel height and width at different distances from the supply vent: a Plane $\mathrm{Y}=0 \mathrm{~m} ; \mathbf{b}$ Plane $\mathrm{Z}=3.4 \mathrm{~m}$
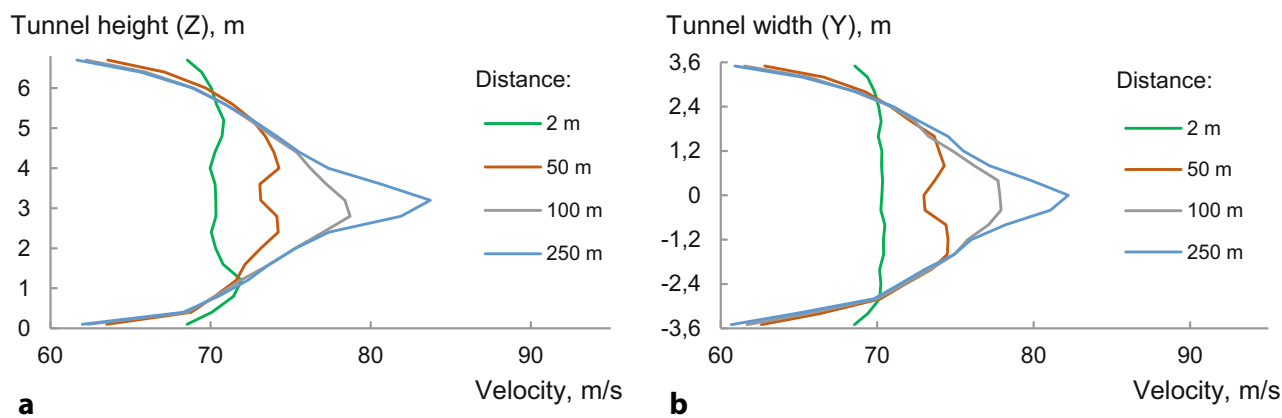

In the process, a new approach to estimate the stability of the model predictions introducing the standard deviation, obtained from the calculated time-averaged pressure values, is proposed.

For example, the considered parameter combinations of the initial time step DT $(0.001$ and $0.002 \mathrm{~s})$ and PRESSURE_TOLERANCE $\left(5,10,20\right.$, and $\left.40 \mathrm{~s}^{-2}\right)$ provide no significant impact on the calculated standard deviations with the significance level of 0.05 (Fig. 6a). Meanwhile, for the other DT values $(0.005,0.01,0.05,0.1 \mathrm{~s})$, the common tendency of higher pressure tolerances leading to the increased standard deviation values is observed (Fig. 6b).

The proposed approach allows specifying the appropriate DT-PRESSURE_TOLERANCE combination considering the desired consistency of results and the time consumed on calculations.

Based on the conducted sensitive analysis and in accordance with the objectives of the study, the following values of the reviewed parameters are chosen: $\mathrm{DT}=0.05 \mathrm{~s}$, PRESSURE_TOLERANCE $=40 \mathrm{~s}^{-2}$, MAX_PRESSURE_ITERATIONS $=50$.

\section{Results and Discussion}

The modelling process is conducted within two stages - from a simple case of an empty tunnel to a more complicated scenario when a train impact on pressure distribution inside a tunnel is considered. 


\subsection{Prediction of Aerodynamic Parameters for the "Empty Tunnel" Case}

The tunnel model without a train inside is reviewed to estimate aerodynamic parameters through the 15 s time simulation.

The predicted pressure values at the centerline and side positions, as well as the mean pressure for the tunnel cross-sections, fully correspond to the trend established at the previous stage of the study-pressure losses decrease within the tunnel length and reduce to zero at the tunnel opening.

The results show an increase (up to $13.5 \mathrm{~m} / \mathrm{s}$ ) in the centerline velocity and a decrease (up to $1.5 \mathrm{~m} / \mathrm{s}$ ) in the side velocity from the initial value $(69.44 \mathrm{~m} / \mathrm{s})$. Meanwhile, the mean velocity for the tunnel cross-sections stays on a constant level along the tunnel. The profiles of vertical and horizontal velocity distribution inside the tunnel at different distances from the supply vent are presented in Fig. 7.

The simulation shows that the volume flow inside the tunnel after the settling period (4-5s) meets the original value $\left(2899.8 \mathrm{~m}^{3} / \mathrm{s}\right)$ and keeps it at the same level. The find- ings correspond well with the theory regarding a constant mass flow rate through a tunnel [29].

\subsection{Prediction of Aerodynamic Parameters for the "Train Inside the Tunnel" Case}

The performed background allows increasing the simulation complexity by adding the train model into the setup (simulation time is $20 \mathrm{~s}$ ). Three distances $(60,120$, and $180 \mathrm{~m}$ ) between the supply vent and the train's nose are considered.

Depending on the train position inside the tunnel, three side pressure profiles are obtained (Fig. 8). The similarity in all cases allows concluding that the resulted pressure changes have an equal magnitude that is not affected by the train geometrical positioning in the tunnel.

Calculations show a significant mean velocity rise and mean pressure drop due to the train's nose emerging and the opposite behaviour by virtue of the train's tail.

The actual pressure change caused directly by the train placed inside the tunnel is visible through comparing two
Fig. 8: Impact of the train position on the side pressurevalues along the tunnel
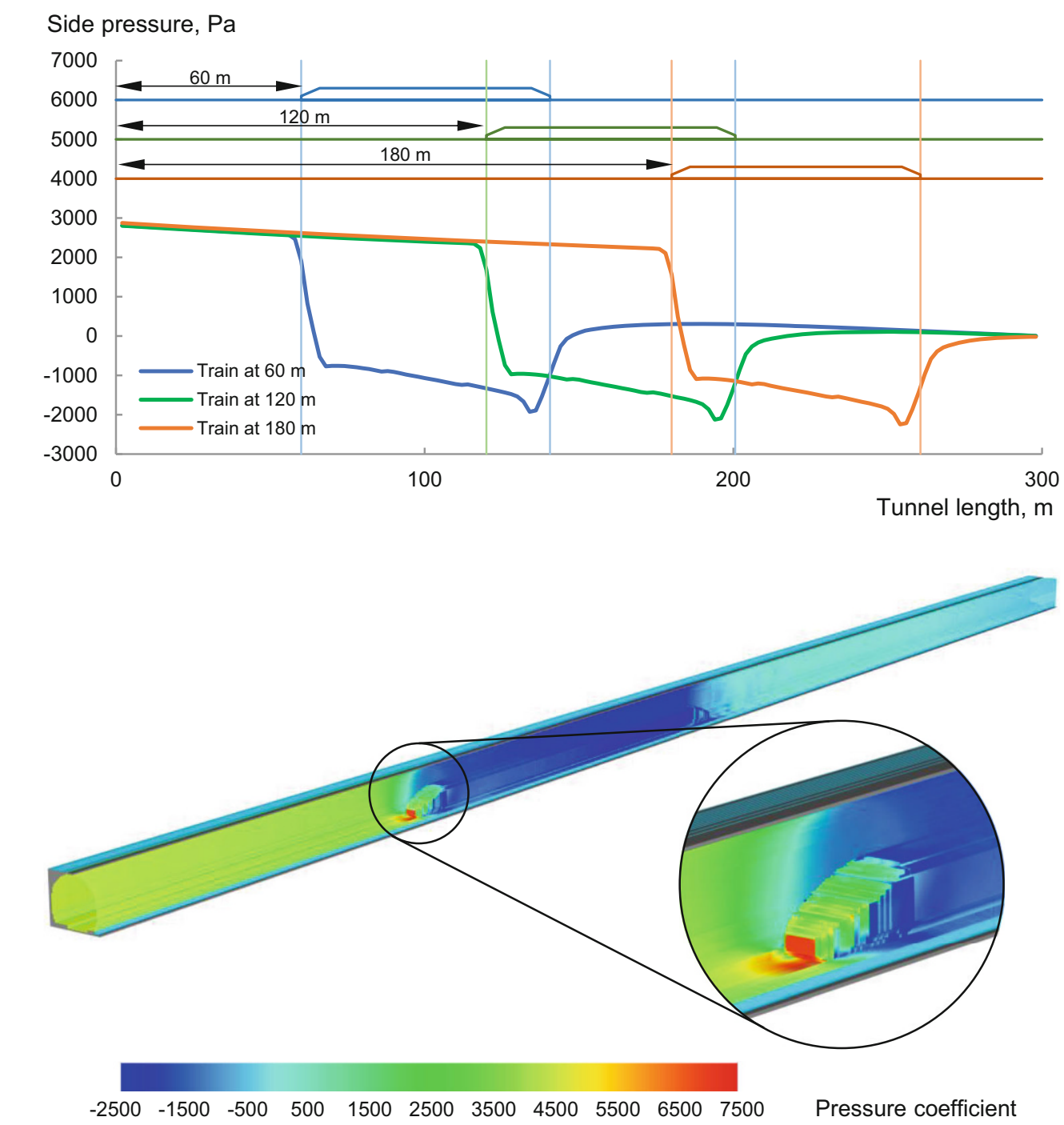

Fig. 9: Pressure coefficient values at all tunnel and train surface points (at $18 \mathrm{~s}$ of the simulation) by the example of a train placed at a distance of $60 \mathrm{~m}$ from the supply vent 
Fig. 10: Impact of the length ratio on pressure losses

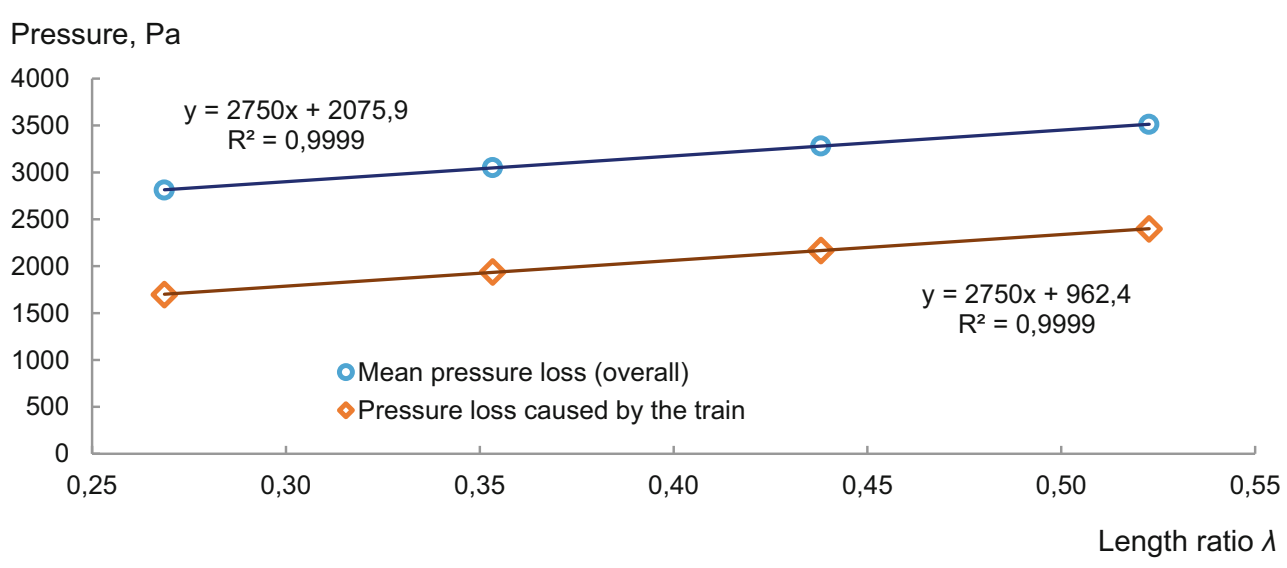

\begin{tabular}{|lll|}
\hline $\begin{array}{l}\text { TABLE } 2 \\
\text { Trains characteristics }\end{array}$ & & \\
\hline Train description & Train length $L_{t r}, \mathrm{~m}$ & Length ratio $\lambda$ \\
\hline Train 1 (3 cars in total) & 80.6 & 0.269 \\
\hline Train 2 (4 cars in total) & 106 & 0.353 \\
\hline Train 3 (5 cars in total) & 131.4 & 0.438 \\
\hline Train 4 (6 cars in total) & 156.8 & 0.523 \\
\hline
\end{tabular}

pressure profiles for the considered cases ("empty tunnel" and "train inside the tunnel"). For example, side pressure changes caused by the train presence lie within the range $+1.7 \ldots-2.5 \mathrm{kPa}$.

To show the pressure distribution inside the tunnel, the inner tunnel surfaces additionally to the surfaces of the train carriages are painted using the pressure coefficient values (Fig. 9).

This way of data representation enables the quick finding of the areas with higher and lower pressure loads. It could be useful in circumstances when load capacities on certain surfaces or the reliability of the installed constructions inside a tunnel are analysed.

The magnitude of the pressure drop in the tunnel is affected by the train length that leads to the "pressure-length ratio" dependency in terms of the maximum pressure loss determination [31]. The length ratio $\lambda$ is defined as:

$$
\lambda=\frac{L_{\text {tr }}}{L_{\text {tun }}}
$$

Where $L_{t r}$ is the length of the train $(\mathrm{m})$ and $L_{t u n}$ is the length of the tunnel (m).

In addition to the initial train with only one passenger's carriage, three trains of different lengths are examined. The characteristics of the trains are given in Table 2. The distance between the supply vent (the tunnel entry) and the train's nose is $60 \mathrm{~m}$.

A clear dependency between the pressure loss magnitude and the train length is obtained from the conducted calculations. The overall mean pressure losses in the tunnel and the pressure losses caused by the train presence form a linear relationship with the tunnel-train length ratio (Fig. 10).

\section{Conclusion and Outlook}

The applied "wind tunnel" approach allows studying the aerodynamic performance of a high-speed train in a railway tunnel using FDS. The conditions of a moving train are replicated with a fair degree of certainty regarding the main parameter of the research interest-pressure. A number of preliminary simulations provided a background to improve the initially chosen model setup to achieve acceptable convergence for the predicted and analytically obtained parameter values.

Two scenarios ("empty tunnel" and "train in the tunnel") are simulated to generate data on the aerodynamic parameters inside the tunnel. Velocity distribution and pressure pattern along the tunnel are predicted. For example, the maximal $(+5 \mathrm{kPa})$ and minimal $(-3.5 \mathrm{kPa})$ pressure loads are observed at the front surface of the train nose and on the inclined surface of the train tail, respectively.

The conducted study provides a platform for further research of more complicated scenarios where a model would consider additional factors, from qualitative and quantitative characteristics (i.e., the roughness of the tunnel surfaces) to constructional changes (introduction of auxiliary or technological structures).

Finally, it is worth noting that, despite obvious limitations, FDS could be considered as a valuable modelling tool, though its capabilities must be carefully correlated with the tasks to solve in order to apply the optimal approach in each specific case.

Funding. Open access funding provided by Montanuniversität Leoben.

Open Access This article is licensed under a Creative Commons Attribution 4.0 International License, which permits use, sharing, adaptation, distribution and reproduction in any medium or format, as long as you give appropriate credit to the original author(s) and the source, provide a link to the Creative Commons licence, and indicate if changes were made. The images or other third party material in this article are included in the article's Creative Commons licence, unless indicated otherwise in a credit line to the material. If material is not included in the article's Creative Commons licence and your intended use is not permitted by statutory regulation or exceeds the permitted use, you will need to obtain permission directly from the copyright holder. To view a copy of this licence, visit http://creativecommons.org/licenses/by/4.0/. 


\section{References}

1. Guigon, M.: The perpetual growth of high-speed rail development, https://www.globalrailwayreview.com/article/112553/perpetualgrowth-high-speed-rail/ (06.05.2021)

2. Wang, L.; Acheampong, R. A.; He, S.: High-speed rail network development effects on the growth and spatial dynamics of knowledge-intensive economy in major cities of China, Cities, 105 (2020), 102772, https://doi.org/10.1016/j.cities.2020.102772

3. Bharule, S.; Kidokoro, T.; Seta, F.: Evolution of high-speed rail and its development effects: Stylized facts and review of relationships, ADBI Working Paper, no. 1040 (2019), https://www.adb.org/sites/ default/files/publication/539751/adbi-wp1040.pdf (10.05.2021)

4. Baker, C. J.: A review of train aerodynamics Part 1-Fundamentals, The Aeronautical Journal, 118 (2014), no. 1201, pp 201-228, https:// doi.org/10.1017/S000192400000909X

5. Baker, C. J.: A review of train aerodynamics Part 2-Applications, The Aeronautical Journal, 118 (2014), no. 1202, pp 345-382, https:// doi.org/10.1017/S0001924000009179

6. Niu, J.; Sui, Y.; Yu, Q.; Cao, X.; Yuan, Y.: Aerodynamics of railway train/tunnel system: A review of recent research, Energy and Built Environment, 1 (2020), pp 351-375, https://doi.org/10.1016/j.enbenv. 2020.03.003

7. Meng, S.; Zhou, D.; Wang, Z.: Moving model analysis on the transient pressure and slipstream caused by a metro train passing through a tunnel, PLoS ONE, 14 (2019), no. 9, e0222151, https://doi. org/10.1371/journal.pone.0222151

8. Rashidi, M.; Hajipour, A.; Li, T.; Yang, Z.; Li, Q.: A Review of Recent Studies on Simulations for Flow around High-Speed Trains, Journal of Applied and Computational Mechanics, 5 (2019), no. 2, pp 311-333, https://doi.org/10.22055/jacm.2018.25495.1272

9. Niu, J.; Zhou, D.; Liu, F.; Yuan, Y.: Effect of train length on fluctuating aerodynamic pressure wave in tunnels and method for determining the amplitude of pressure wave on trains, Tunnelling and Underground Space Technology, 80 (2018), pp 277-289, https://doi. org/10.1016/j.tust.2018.07.031

10. Ko, Y.-Y.; Chen, C.-H.; Hoe, I.-T.; Wang, S.-T.: Field measurements of aerodynamic pressures in tunnels induced by high speed trains, Journal of Wind Engineering and Industrial Aerodynamics, 100 (2012), no. 1, pp 19-29, https://doi.org/10.1016/j.jweia.2011.10.008

11. Liu, T.; Chen, Z.; Chen, X.; Xie, T.; Zhang, J.: Transient loads and their influence on the dynamic responses of trains in a tunnel. Tunnelling and Underground Space Technology, 66 (2017), pp 121-133, https://doi.org/10.1016/j.tust.2017.04.009

12. Somaschini, C.; Argentini, T.; Brambilla, E.; Rocchi, D.; Schito, P.; Tomasini, G.: Full-Scale Experimental Investigation of the Interaction between Trains and Tunnels, Applied Sciences, 10 (2020), no. 20, 7189, https://doi.org/10.3390/app10207189

13. Sanok, S.; Mendolia, F; Wittkowski, M.; Rooney, D.; Putzke, M.; Aeschbach, D.: Passenger comfort on high-speed trains: effect of tunnel noise on the subjective assessment of pressure variations, Ergonomics, 58 (2015), no. 6, pp 1022-1031, https://doi.org/10.1080/ 00140139.2014 .997805

14. EN 14067-3. Railway Applications-Aerodynamics-Part 3: Aerodynamics in Tunnels, Brussels: European Committee for Standardization (CEN), 2003

15. EN 14067-5. Railway Applications-Aerodynamics-Part 5: Requirements and Test Procedures for Aerodynamics in Tunnels, Brussels: European Committee for Standardization (CEN), 2006
16. Li, W.; Liu, T.; Chen, Z.; Guo, Z.; Huo, X.: Comparative study on the unsteady slipstream induced by a single train and two trains passing each other in a tunnel, Journal of Wind Engineering and Industrial Aerodynamics, 198 (2020), 104095, https://doi.org/10.1016/ j.jweia.2020.104095

17. Huang, S.; Che, Z.; Li, Z.; Jiang, Y.; Wang, Z.: Influence of tunnel cross-sectional shape on surface pressure change induced by passing metro trains, Tunnelling and Underground Space Technology, 106 (2020), 103611, https://doi.org/10.1016/j.tust.2020.103611

18. Yang, W.; Deng, E.; Zhu, Z.; He, X.; Wang, Y.: Deterioration of dynamic response during high-speed train travelling in tunnel-bridgetunnel scenario under crosswinds, Tunnelling and Underground Space Technology, 106 (2020), 103627, https://doi.org/10.1016/j.tust. 2020.103627

19. Banerjee, D.; Yeo, D.; Hemley, S.; McDermott, R.; Lombardo, F. Simiu, E.; Levitan, M.: Practical CFD Simulations of Wind Tunnel Tests, in: Proceedings of 12th Americas Conference on Wind Engineering, USA, Seattle, 2013, [online], https://tsapps.nist.gov/ publication/get_pdf.cfm?pub_id=913723 (10.05.2021)

20. Miao, X.; He, K.; Minelli, G.; Zhang, J.; Gao, G.; Wei, H.; He, M.; Krajnovic, S.: Aerodynamic Performance of a High-Speed Train Passing through Three Standard Tunnel Junctions under Crosswinds, Applied Sciences, 10 (2020), no. 11, 3664, https://doi.org/10.3390/ app 10113664

21. Baturin, V. V.: Fundamentals of Industrial Ventilation, 3. ed., translated by O. M. Blunn, New York: Pergamon Press Oxford, 1972

22. Eck, B.: Technische Strömungsmechanik: Berlin, Heidelberg: Springer, 2007, https://doi.org/10.1007/978-3-662-00793-8

23. Ricou, F. P.; Spalding, D. B.: Measurements of entrainment by axisymmetrical turbulent jets, Journal of Fluid Mechanics, 11 (1961), no. 01, pp 21-32, https://doi.org/10.1017/s0022112061000834

24. McGrattan, K. et al.: Fire Dynamics Simulator User's Guide, 6. ed., Gaithersburg, Maryland: National Institute of Standards and Technology, 2020, https://doi.org/10.6028/NIST.SP.1019

25. McGrattan, K. et al.: Fire Dynamics Simulator Verification Guide, vol. 2, 6. ed., Gaithersburg, Maryland: National Institute of Standards and Technology, 2020, https://doi.org/10.6028/NIST.SP.1018

26. Patterson, N.: Assessing the Feasibility of Reducing the Grid Resolution in FDS Field Modelling, Research Rep. 02/12: University of Canterbury, 2002

27. Vermesi, I.; Rein, G.; Colella, F.; Valkvist, M.; Jomaas, G.: Reducing the computational requirements for simulating tunnel fires by combining multiscale modelling and multiple processor calculation, Tunnelling and Underground Space Technology, 64 (2017), pp 146-153, https://doi.org/10.1016/j.tust.2016.12.016

28. Yang's Research: High-Speed Train-Tunnel Interactions, http://www. ms.t.kanazawa-u.ac.jp/ fluid/staff/yang/train.html (09.02.2021)

29. Munson, B. R. et al.: Fundamentals of Fluid Mechanics, 6. ed.: John Wiley \& Sons, 2009

30. Swamee, P. K.; Jain, A. K.: Explicit equations for pipe-flow problems, Journal of the Hydraulics Division, 102 (1976), no. 5, pp 657-664

31. Ledyaev, A.; Kavkazskiy, V.; Vatulin, Y.; Svitin, V.; Shelgunov, O.: Mathematical modeling of aerodynamic processes in railway tunnels on high-speed railways, E3S Web of Conferences, 157 (2020), 06017, https://doi.org/10.1051/e3sconf/202015706017

Publisher's Note. Springer Nature remains neutral with regard to jurisdictional claims in published maps and institutional affiliations. 